\title{
Stendhal, La Chartreuse de Parme
}

\section{Lise Sabourin}

\section{(2) OpenEdition}

\section{Journals}

\section{Édition électronique}

URL : http://journals.openedition.org/studifrancesi/34837

DOI : $10.4000 /$ studifrancesi.34837

ISSN : 2427-5856

\section{Éditeur}

Rosenberg \& Sellier

\section{Édition imprimée}

Date de publication : 1 novembre 2005

Pagination : 429

ISSN : 0039-2944

\section{Référence électronique}

Lise Sabourin, « Stendhal, La Chartreuse de Parme », Studi Francesi [En ligne], 146 (XLIX | II) | 2005, mis en ligne le 30 novembre 2015, consulté le 19 avril 2021. URL : http://journals.openedition.org/ studifrancesi/34837 ; DOI : https://doi.org/10.4000/studifrancesi.34837

\section{Ce document a été généré automatiquement le 19 avril 2021.}

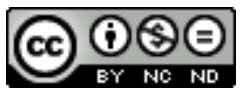

Studi Francesi è distribuita con Licenza Creative Commons Attribuzione - Non commerciale - Non opere derivate 4.0 Internazionale. 


\title{
Stendhal, La Chartreuse de Parme
}

\author{
Lise Sabourin
}




\section{RÉFÉRENCE}

STENDHAL, La Chartreuse de Parme, édition de MARIELla DI MAIO, Paris, Gallimard, 2003

(«Folioclassique»), pp. 753.

Cette réédition en format de poche présente l'avantage d'être préfacée et annotée par Mariella Di Maio, professeur à l'Université de Rome III, qui enrichit sa lecture de l'apport de toute sa culture italienne. Outre la chronologie, une notice sur l'histoire du texte, des notes précises (dont certaines de variantes textuelles), elle présente les documents liés à la genèse (la nouvelle sur l'Origine des grandeurs de la famille Farnèse, l'Acte de vengeance commis par le cardinal Aldobrandini sur la personne de Girolamo Longobardi chevalier romain et la pseudo-lettre stendhalienne du 27 août 1832 sur La Jeunesse d'Alexandre Farnèse) et à la réception du roman (les principaux extraits de l'article de Balzac dans la Revue parisienne du 25 septembre 1840 et la réponse épistolaire de Stendhal). Mais, loin de s'arrêter à cette "apothéose in vita» (p. 9) qui nourrit par ailleurs la Catherine de Médicis balzacienne, à l'étude de la fortune littéraire ultérieure de La Chartreuse ou à la revue de ses personnages, la synthèse présentée par M. di Maio confirme les propos de Lampedusa et Calvino sur ce «plus italien des romans français» (p. 8). Fascination pour la jeunesse de Paul III, tendre allégresse du Matrimonio secreto de Cimarosa, imprégnation «tutélaire» de l'Arioste, souvenir claustral de Benvenuto Cellini au château Saint-Ange, "génie mélancolique et voluptueux» du Tasse, vœu de Clélia détourné subtilement des Fiancés de Manzoni: toute cette «matière d'Italie» permet au rescapé de la retraite de Russie et de la débâcle napoléonienne après Waterloo de "dire ce qui n'est pas dicible» (p. 20). Écrire la fin d'un monde n'est possible que grâce à l'ironie qui exalte le sombre bonheur du prisonnier de la tour imaginaire de Parme, sous une botte autrichienne qui n'oblitère pas la grandeur des chroniques de la Renaissance. 